\title{
Ectocervical Mucosa
}

National Cancer Institute

\section{Source}

National Cancer Institute. Ectocervical Mucosa. NCI Thesaurus. Code C33990.

The mucous covering of the vaginal portion of the cervix. It is composed of epithelium, basement membrane, lamina propria mucosae, and lamina muscularis mucosae. 